\title{
'PEER PHYSICAL EXAMINATION' AS A TOOL FOR LEARNING HUMAN ANATOMY AND CLINICAL SKILLS
}

\section{Archana Damodharrao Kannamwar ${ }^{1}$, Gajanan Laxmanrao Maske ${ }^{* 2}$.}

${ }^{1}$ Associate Professor, Anatomy, SVNGMC, Yavatmal.445001, India.

${ }^{* 2}$ Assistant Proessor, Anatomy, SVNGMC, Yavatmal.445001, India.

\section{ABSTRACT}

Background: Academic achievement is considered as a key to judge one's potentialities and capacities. Low achievement may be related to poor self concept, lack of family involvement, damaging peer pressure, cultural deprivation, study skill deficiency, emotional problems, physical illness, lack of academic motivation. Anatomy has been considered a key element of medical education for centuries and has survived current challenging pedagogic test of time. The teaching hours of anatomy have been reduced but the traditional teaching predominates and lacks integration and clinical correlate. As living and surface anatomy forms the bridge between clinical practice and gross anatomy; the reduced course hours compelled many medical institutes to upgrade the development of anatomical resources via new technological advancements and by inculcating living anatomy sessions by peer examination, life models and imaging. Further evidence is needed to define which method of anatomy teaching leads to the most effective clinicians and if the choice of method affects students. Peer physical examination (PPE) was considered as one of the important and widely accepted teaching tool in conducting living and surface anatomy sessions. In the present study, PPE is used as a teaching tool to help low achiever students to escalate their academic performance.

Results: Two groups A and B are made of 25 each from 50 low achiever students. Five topics of living anatomy were taught with traditional method in group A and with PPE in group B. Then students were assessed by objectively structured practical examination (OSPE) of both groups. There was statistically significant difference in scores of students in group A and group B.

Conclusions: So we concluded that there is definitely an academic improvement in the low achiever students with the use of PPE. But future studies are required to compare the findings presented here with those of other medical colleges. So that PPE can be included as a regular teaching tool to facilitate not only low achievers but all of the students for their academic enhancement and future goal of becoming competent and ideal clinician.

KEY WORDS: Low achievers, PPE, Living Anatomy, Academic improvement.

Address for Correspondence: Dr. Gajanan L. Maske, Assistant Proessor, Anatomy, SVNGMC, Yavatmal.445001, India. E-Mail: drgajananlmaske@gmail.com

Quick Response code

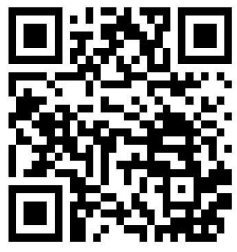

DOI: $10.16965 /$ ijar.2019.127
Journal Information

\begin{tabular}{|c|c|c|}
\hline \multicolumn{3}{|c|}{ Journal Information } \\
\hline \multicolumn{3}{|c|}{$\begin{array}{l}\text { International Journal of Anatomy and Research } \\
\begin{array}{|l}\text { ICV for 2016 ISSN (E) 2321-4287 | ISSN (P) 2321-8967 }\end{array}\end{array}$} \\
\hline \multicolumn{3}{|c|}{ Article Information } \\
\hline $\begin{array}{l}\text { Received: } 28 \text { Jan } 2019 \\
\text { Peer Review: } 28 \text { Jan } 2019 \\
\text { Revised: None }\end{array}$ & $\begin{array}{l}\text { Accepted: } 07 \text { Mar } \\
\text { Published (O): } 05 \\
\text { Published (P): } 05\end{array}$ & $\begin{array}{l}19 \\
2019 \\
2019\end{array}$ \\
\hline
\end{tabular}

\section{INTRODUCTION}

Anatomy provides platform of knowledge indispensable to all the branches of medicine. In spite of this, the pre-clinical sciences remains challenged to find teaching strategies that actively engage students in the learning process.
Because anatomy is a subject in which students have to learn many new concepts and complex terminologies making it difficult, monotonous and painstaking [1]. The other important reason is that, the hours allocated for the teaching of Anatomy have been abruptly reduced in 
the recent medical curricula. So there is need of careful planning to include students- directed anatomy objectives in the curriculum and its implementation [2].

The most important difficulty for medical faculties is that, students are extremely diverse with respect to their grades, their abilities, their cultural backgrounds and professional fields. Hence it remains a challenge to find and assess methods to teach all students anatomy more effectively, in less time, and often with limited resources $[1,3]$.

This project describes two themes within the undergraduate medical curriculum; innovations in anatomy teaching, and the assessment of professionalism especially for low achiever students.

Low achiever or slow learners [4]: Low achievement is defined as a discrepancy between the child's actual ability and achievement. Multiple factors are responsible for it with the level of confidence and learning environment playing an important role. 'Failure to recognize problems and provide solutions' is also reported to be contributory factors.

Ways to teach Anatomy [1,2,5]: There has been ongoing debate as to the best way to teach anatomy for many decades, whether it be by dissection, pro-section or the use of new technologies.

Living Anatomy: Living anatomy is the observation of the living body as opposed to the observation of cadaveric anatomy. In practice, medics encounter the patient as a living and moving being. This is in stark contrast to the cadaver, from which most medical students learn their anatomy.

Literature recording the teaching of living anatomy dates back to books by Robinson (1928) and Lockhart (1947) describe and depict living anatomy. Some of the earliest recordings of living anatomy date back to the eighteenth century and John Hunter. Recommendations for the teaching of living anatomy were made by the General Medical Council in 1930, "the demonstration of structure and function in the living should form an integral part of medical student's professional training (cited in Waterson 1931). Living anatomy teaching sessions can take many forms. Current methods include peer-physical examination, body painting and various types of imaging and scanning. Techniques such as imaging and examination are utilised within the practitioner's setting; examining a patient is an exercise in living anatomy $[6,7]$.

Teaching Methodologies: Clinicians often blame anatomists for teaching students too many details and not enough clinically relevant structures. Traditional methods are didactic and include the students dissecting cadavers. More recently, medical schools have moved away from cadaveric dissection in favour of using pro- sections, living anatomy and plastic models. Teaching has moved from traditional, teacher-led lectures and practical, to more integrated approaches such as Problem-Based Learning (PBL) or case-based learning (CBL).

Peer Physical Examination (PPE): PPE bears many similarities to the use of life models; namely that students can assuage their own anxiety in performing examinations through repeated practice in a safe environment and they can view a wide range of body morphologies. One advantage of PPE is that it is less expensive than using life models and easier to organise. Also, by being examined themselves, students appreciate what it feels like to be examined. This will assist them in understanding the anxieties a patient may experience $[3,8]$.

Objective Structured Clinical / Practical Examinations $[9,10]$ : Professionalism is a complex and dynamic concept that is influenced by a wide range of factors. By ignoring assessment of professionalism faculty runs the risk of doing a disservice to society. The challenge present is the absence of a set of measurement instruments. Objective Structured Clinical Examinations (OSCEs) and Objective Structured Practical Examinations (OSPEs) have been described as an assessment method for professionalism. These examinations, primarily utilised for assessing a candidate's practical and clinical examination and communication skills, present scenarios which are usually delivered by a simulated patient. Thus, PPE is a method of teaching and learning living anatomy and clinical skills where students act as model patients for one another to allow practice of physical examination techniques rather than 
traditional method involving subjects ( live models). In this study PPE is only approved for non-intimate body region examination. Genital, groin, breast or rectal examinations are not undertaken as peer physical examination. All examination sessions will have a facilitator present to facilitate and support student learning. This prospective comparison of 2 educational strategies measures an objective outcome especially in low achievers: students' performance on examination questions through OSPE.

\section{MATERIALS AND METHODS}

Ethical approval: Ethical approval was taken from the Institutional Ethics Committee of Shri. Vasantrao Naik Government medical college, Yavatmal.

Study design: It was an interventional study

Sample size and population: Sample size was of 50 first year medical students among the population of 150 students

Sampling technique: convenient sampling

The 150 First MBBS students were arranged in descending order according to their marks in terminal examination. Then they were divided into three categories as following:

- Category I: First 50 students in the list as "High achiever"

- Category II: Middle 50 students as "Medium achiever"

- Category III: Last 50 students as "low achiever"

Inclusion criteria: Students belonging to category III

Exclusion criteria: Students belonging to category I and II

Method / plan of study: It was an Interventional study in which mixed qualitative and quantitative methods were used.

Sensitization of departmental teaching staff was done about concept \& method of "peer physical examination" as a tool for teaching living Anatomy with the help of lecture cum demonstration.

Sample size of 50 students were selected by convenient sampling method described above.A workshop of teaching faculty and those selected 50 MBBS Students was taken about
"OSPE" with the help of lecture cum demonstration. ${ }^{10}$

Five topics of living Anatomy were taken, one from each region of human anatomy.

Five teachers were trained for working as 'facilitator' in next step

They were given ground rules about "dos \& don'ts" while acting as a facilitator

Do's:

- Bring the students to right path, by avoiding irrelevant behaviour

- Correction of any mistake during peer physical examination

\section{Don'ts}

- Do not teach

- Do not encroach on students

- Do not intervene unnecessarily

\section{Intervention:}

These 50 students were divided into two groups 'A' \& 'B'.

For group 'A' Group 'A'

- Group ' $A$ ' were taught selected living anatomy topics by traditional method by using a live model as a subject

- Group ' $B$ ' were be taught selected living anatomy topics by traditional method by using a live model as a subject

- Then they were divided into 5 subgroups with a trained facilitator for each group.

- Students from each subgroup done physical examination of their fellow students for learning the whole technique of given topic correctly under supervision of facilitator.

- For assessment of these students 'OSPE' was taken

- Group " $A$ " was taught same topics with new tool of 'peer physical examination' to maintain ethical balance.

Data Analysis: Quantitative data analysis was done with the help of Microsoft excel. Based on the variables statistical method of 'Students t-test 'was applied and ' $p$ value' was calculated.

\section{RESULTS}

The marks obtained by the students in objectively structured practical examination by the 
students of 'Group A' which studied topics of living anatomy by traditional way were significantly lesser than the 'Group B' students who studied those topics with the newer teaching tool used for living Anatomy i.e. 'peer physical examination".

Table 1:

\begin{tabular}{|c|c|c|c|c|}
\hline \multicolumn{5}{|c|}{ Group A OSPE Marks of students studied by traditional } \\
method
\end{tabular}

Table 2:

\begin{tabular}{|c|c|c|c|c|}
\hline \multicolumn{5}{|c|}{ Group B OSPE Marks of students studied by peer physical } \\
examination
\end{tabular}

Table 3:

\begin{tabular}{|c|c|c|c|c|c|}
\hline Procedures in & & Group A & Group B & t-value & $\mathrm{p}$-value \\
\hline \multirow{2}{*}{ Procedure I } & Mean & 5.94 & 8.94 & \multirow{2}{*}{-6.94924} & \multirow{2}{*}{$<.00001$} \\
\cline { 2 - 5 } & SD & 2.047966 & 0.681909 & & \\
\hline Procedure II & Mean & 6.06 & 8.42 & -8.30074 & $<.00001$ \\
\hline \multirow{2}{*}{ Procedure III } & Mean & 4.86 & 7.16 & \multirow{2}{*}{-5.22817} & $<.00001$ \\
\cline { 2 - 4 } & SD & 1.326963 & 1.75428 & & \\
\hline
\end{tabular}

Table 4:

\begin{tabular}{|c|c|c|}
\hline Total score & Group A & Group B \\
\hline Average & 7.16 & 16.89 \\
\hline S.D. & 1.9940168 & 2.779089 \\
\hline t value & \multicolumn{2}{|c|}{11.22035} \\
\hline p value & \multicolumn{2}{|c|}{$<.00001$} \\
\hline
\end{tabular}

As we can see from following tables, this difference is statistically significant as shown by the values of' .'t-test' and 'p-value'.

\section{DISCUSSION}

Education is a unique investment and academic achievement is a vital aspect of it. Hence, educators give paramount credence to the intellectual attainment of the student in the form of grades and scorings, and had equated education to the age-old idea of imparting knowledge to the disciples.

As per Kannan L et al (2015), the generally accepted individual factors conducive for academic achievement are intelligence, personality, study skills, and motivational level of the concerned student. The family and the school are also important social factors. In present study, we are motivating the low achievers by giving them hands on approach and telling them application of their knowledge and its future prospectus [4].

Another important aspect of low achievement is stress. As per Sajid A et al (2015), it is a common belief that medical profession is a stressful field and this stress starts right from the very first day when a student enters the medical school. Though a certain degree of stress is considered to be a part and parcel of the medical profession, academically, stress can be motivating for some, but may prove otherwise for rest of the students. Vastness of curriculum and high pace of studies were also reported as very often leading to stress [11].

This highlights the need of changing the teaching methodology, modifying the lecture style or 
converting the lectures into group discussions so that it becomes more palatable for our medical students, which we have tried here.

In our study, informed written consent was taken; we gave them adequate choice of peer-group they want. We told them the positive aspects associated with the physical examination such as skills and attitude development, integration of theory and practice, and acquiring precise knowledge of anatomical landmarks. All this was in the set up having their friends and teacher as facilitator without any burden and questioning, so they felt comfortable and became more interested and attentive in the class.

When we talk about anatomy, Mclachlan J C et al (2006), Collett T et al (2009) and Sawant S P et al (2015) said that anatomy is the base of medical science and is taught practically to all disciplines of undergraduate health sciences in the first year. So proper utilization of newer technologies along with the traditional teaching methods will certainly lead to enhanced understanding of gross anatomy and will ultimately improve students' performance $[5,6,1]$.

According to Duvivier R J et al (2009), teachers should actively engage students in their learning and encourage them to provide meaning and relevance to clinical skills taught [12].

In this scenario' PPE' remained as milestone. So, in the present study we are trying to use 'PPE' as a pedagogic tool for low achievers. Our effort is to increase their interest, attentiveness and to give them hands on approach which ultimately leads to their improved academic scores as well as personality development as a future clinician. From a financial standpoint, PPE incurs no cost as compared with simulated patients and high-fidelity simulators.

In his study, Koles $\mathrm{P}$ et al 2005 demonstrates that TBL (Team based learning) and CBGD (Case based group discussion) may selectively benefit students with lower academic achievement more than higher achievers, evidenced in this study by better retention of knowledge among lowest quartile students between an active learning event and the end-of-course examination [13].

Extensive researches, published in the last two decades, has shown definitely and beyond question that peer programs can have statistically significant effects on attitudes, norms, knowledge, behaviours and achievement outcomes [1].

In the present study also, we see the significant difference in the academic scores in the examination, taken after teaching the living anatomy by 'PPE'. Because of active learning involving peers, they have easily understood the topics as well as it leads to better retention of knowledge and its timely reproduction in the form of performance in the examination. [Table 1-4]

Consorti F et al (2012), reported that defining professionalism and explicitly integrating professionalism into the medical curriculum presents a difficult challenge [14]. That is why we decide to introduce PPE in living anatomy and do the assessment by OSPE, in which professionalism can also be assessed.

Henning J M (2008) reported that Medical students serving as peer teachers in a laboratory setting reported improved study habits and better attitudes towards the subject matter and also improved their communication skills, and increased their self-confidence [15].

At the end we could state some limitations of this study. The categorization of low achievers was done based on the marks in terminal examination only. However, the investigator would have felt more satisfied if we could involve marks of set of two three examinations rather than from single examination. The extent to which the findings from this study are generalisable is doubtful as the study was confined to the experiences and perceptions of students in one medical college only.

Suggestions for further research: Further evidence is needed to define which method of teaching anatomy leads to the most effective clinicians and if the choice of method affects student selection.

\section{CONCLUSION}

Our data from our sample of students showed that there is definitely an academic improvement in the low achiever students with the use of PPE, but this activity should nevertheless be carefully designed and introduced before being implemented. Furthermore participation in PPE 
for medical students should be voluntary and non-coercive, practices in group with students able to choose their own groups or partner and it must be supported by staff training.

\section{ACKNOWLEDGEMENTS}

I would like to express my sincere gratitude to my advisor Professor Dr. Jayant Vagha who has been a tremendous mentor for me. I would like to thank my colleagues from my department at SVNGMC Yavatmal for their wonderful collaboration. In addition, I would like to thank Co-ordinator of MEU and Professor \& HOD of Pathology, Dr. Hingway madam for her co- operation and valuable guidance and Dr. Umesh Kawalkar, assistant professor, Preventive and social medicine, who helped me in data analysis and statistics. I would also like to thank my Advance Course in Medical Education (ACME) faculties especially Dr. Sachin Damke, Associate Professor, Paediatrics for brilliant comments and suggestions. Thank you very much, everyone!

\section{Conflicts of Interests: None}

\section{REFERENCES}

[1]. Sawant S P, Rizvi S. Teaching Anatomy to Undergraduate Students. Int J Anat Res 2015; Vol 3(3):1212-15. .

[2]. Asad M R, Nasir N. Role of Living and Surface Anatomy in Current Trends of Medical Education. IJARIIE 2015; Vol-1 Issue-2: 203-209.

[3]. Outram S, Nair B R. Peer physical examination: time to revisit? Med J Aust 2008; 189 (5): 274-276

[4]. Kannan L, Vijayaragavan P V, Dr. Shah P B, Suganathan. S, Praveena .P. Factors Contributing Decreased Performance of Slow Learners. International Journal Of Scientific \& Technology Research. March 2015; Volume 4, Issue 03 :58-61

[5]. McLachlan J C \& Patten D. Anatomy teaching: ghosts of the past, present and future. In Medical Education. Blackwell Publishing Ltd 2006; 40: 243-253.
[6]. Collett T, Kirvell D, Nakorn A, McLachlanJ C. The role of living models in the teaching of surface anatomy: Some experiences from a UK Medical School. Medical Teacher; 2009: 31:3, e90-e96, DOI: 10.1080/ 01421590802516731.

[7]. Chen J Y, Amber L.M.Yip, Cindy L.K. Lam and Patil N G. Does medical student willingness to practise peer physical examination translate into action? ; 2011; Vol. 33, Iss. 10.

[8]. Chinnah TI, De Bere S R \& Collett T. Students 'views on the impact of peer physical examination and palpation as a pedagogic tool for teaching and learning living human anatomy, Medical Teacher; 2011; 33:1.

[9]. Finn, Gabrielle, Maria (2010) Anatomy and Professionalism In An Undergraduate Medical Curriculum. Doctoral thesis, Durham University. Available at Durham E-Theses Online: ttp://etheses.dur.ac.uk/ 539/

[10]. Rushforth H E. Objective structured clinical examination (OSCE): Review of literature and implications for nursing education. DOI: http://dx.doi.org/ 10.1016/j.nedt.2006.08.009

[11]. Sajid A, Ahmad T, Khalid T. Stress in medical undergraduates; its association with academic performance. Bangladesh Journal of Medical Science Vol.14(2) 2015 p.135-141

[12]. Duvivier R J, Dalen J V, Van Der VleutenC P M \& Scherpbier A J J A. Teacher perceptions of desired qualities, competencies and strategies for clinical skills teachers. Medical Teacher. 2009; 31: 634-641.

[13]. Koles P, Stuart Nelson S, Adrienne Stolfi A, Parmelee D \& DeStephen D. Medical Education 2005; 39: 10451055

[14]. Consorti F*, Mancuso R, Piccolo A, Consorti G and Zurlo J. Evaluation of the acceptability of Peer Physical Examination (PPE) in medical and osteopathic students: a cross sectional survey. I. BMC Medical Education 2013, 13:111.

[15]. Henning J M, Weidner T G, Marty M C.Athletic Training Education Journal 2008; 3(Jul-Sep)

How to cite this article:

Archana Damodharrao Kannamwar, Gajanan Laxmanrao Maske. 'PEER PHYSICAL EXAMINATION' AS A TOOL FOR LEARNING HUMAN ANATOMY AND CLINICAL SKILLS. Int J Anat Res 2019;7(2.1):6404-6409. DOI: 10.16965/ijar.2019.127 